\title{
The International Classification of Functioning, Disability and Health (ICF) in Electronic Health Records
}

\section{A Systematic Literature Review}

\author{
Roxanne Maritz ${ }^{1,2}$; Dominik Aronsky33; Birgit Prodinger1,2 \\ ${ }^{1}$ Swiss Paraplegic Research, Nottwil, Switzerland \\ 2University of Lucerne, Dept. of Health Sciences and Health Policy, Lucerne, Switzerland \\ ${ }^{3}$ Dept. of Biomedical Informatics, School of Medicine, Vanderbilt University, Nashville, TN, USA
}

\section{Keywords}

International Classification of Functioning, Disability and Health; Electronic Health Records; Reference Standards; Medical Informatics; Review

\section{Summary}

Background: The International Classification of Functioning, Disability and Health (ICF) is the World Health Organization's standard for describing health and health-related states. Examples of how the ICF has been used in Electronic Health Records (EHRs) have not been systematically summarized and described yet.

Objectives: To provide a systematic review of peer-reviewed literature about the ICF's use in EHRs, including related challenges and benefits.

Methods: Peer-reviewed literature, published between January 2001 and July 2015 was retrieved from Medline ${ }^{\circledR}, \mathrm{CINAHL}^{\circledR}$, Scopus $^{\circledR}$, and ProQuest ${ }^{\circledR}$ Social Sciences using search terms related to ICF and EHR concepts. Publications were categorized according to three groups: Requirement specification, development and implementation. Information extraction was conducted according to a qualitative content analysis method, deductively informed by the evaluation framework for Health Information Systems: Human, Organization and Technology-fit (HOT-fit).

Results: Of 325 retrieved articles, 17 publications were included; 4 were categorized as requirement specification, 7 as development, and 6 as implementation publications. Information regarding the HOT-fit evaluation framework was summarized. Main benefits of using the ICF in EHRs were its unique comprehensive perspective on health and its interdisciplinary focus. Main challenges included the fact that the ICF is not structured as a formal terminology as well as the need for a reduced number of ICF codes for more feasible and practical use.

Conclusion: Different approaches and technical solutions exist for integrating the ICF in EHRs, such as combining the ICF with other existing standards for EHR or selecting ICF codes with natural language processing. Though the use of the ICF in EHRs is beneficial as this review revealed, the ICF could profit from further improvements such as formalizing the knowledge representation in the ICF to support and enhance interoperability.

\section{Correspondence to:}

Roxanne Maritz

Swiss Paraplegic Research

Guido A. Zäch Strasse 4

6207 Nottwil, Switzerland

Tel. +41419396578

roxanne.maritz@paraplegie.ch
Appl Clin Inform 2017; 8: 964-980

https://doi.org/10.4338/ACl-2017050078

received: 9. May 2017

accepted in revised form: 15. July 2017

published: September 20, 2017

Citation: Maritz R, Aronsky D, Prodinger B. The International Classification of Functioning, Disability and Health (ICF) in Electronic Health Records. Appl Clin Inform 2017; 8: 964-980

https://doi.org/10.4338/ACI-2017050078 


\section{Introduction}

Clinical care is evolving and aspires to provide increased levels of personalized care. Personalized clinical care accounts for the specific status of a patient's health, the contextual information about the personalized living situation, and the impact of a health condition on daily life. For this, the need to capture comprehensive health information becomes paramount $[1,2]$. The delivery of personalized care requires patients to be engaged in their healthcare management and entails the greater evolution of shared decision making in routine clinical practice. Information that is accessible to the patient and healthcare providers along the continuum of care becomes essential for such personalized care processes [3]. Electronic health records (EHRs) that support both structured and free text information have the potential to facilitate the depiction, sharing and use of comprehensive health information.

To enable the sharing of information it is important to consider the need for interoperable EHR systems that build upon national and international standards for record structures, coding terminologies and messaging protocols $[4,5]$. Standards on structure and content add a critical dimension to the value of information, as the precise semantics of the information is preserved in computable representation. This supports the exchange of information among different systems [6]. Standards to support semantic interoperability are available and evolving [4]. However, the implementation of such standards in EHRs as a support of clinical care processes remains a substantial challenge [7]. Implementation, as understood in this paper, refers to a planned process and systematic introduction of innovation and changes to optimize the functioning of healthcare organizations [8].

Since 2001, the World Health Organization's (WHO) International Classification of Functioning, Disability and Health (ICF) has been recognized as the international standard for describing health and health-related states. The ICF complements the International Classification of Diseases (ICD) with information about the impact of a health condition on people's functioning in daily life, such as basic activities of daily living but also participation in various life areas, such as employment [9]. Internationally, the ICF has become increasingly present in recent years [10, 11]. Furthermore, functioning as described in the ICF, has been referred to as the third health indicator for monitoring the performance of health systems, next to mortality and morbidity [12]. Similar to the ICD, the ICF is a classification with a hierarchical ordering of concepts [13]. The ICF is among the terminologies listed within the ISO 14639-2 eHealth Roadmap [14] and is also referred to as the standard for describing health in the requirements on quality in healthcare services management in the ISO 9001 [15].

The functional characteristics of the ICF as a terminology have been examined in multiple use cases [16-20]. Some countries have started initiatives using the ICF as a standard of reporting functioning in routine EHRs [18], and evidence suggests that ICF-based documentation adds value in clinical practice [20]. Furthermore, several studies provide evidence that the ICF adequately captures what matters to patients $[16,17]$, and that the ICF is suitable to serve as a starting point for developing standardized record headings [19].

Despite the increasing body of knowledge, there is also evidence that the implementation of the ICF on an operational level is limited [7]. While some organizations have adopted the language of the ICF, it has not yet been implemented as a standard terminology on an operational level [7]. Two previous reviews exist that examined the use and uptake of the ICF. A review on the use of the ICF in clinical practice in general, not focused specifically on EHR, revealed that it is used in a variety of practical and scientific fields, such as rehabilitation and disability eligibility [10]. Such findings provide evidence for the uptake of the comprehensive conceptualization of functioning and disability reflected in the ICF. Another review that specifically targeted the use of the ICF in the Nordic European countries found that there was an increase in ICF relevant papers, especially in the fields of neurology, musculoskeletal, and work-related areas. Nevertheless, the authors concluded that there is still a long way to go before ICF is widely used in rehabilitation and clinical settings [11]. Our review, however, differs from and yet complements these previous reviews by focusing specifically on the use of the ICF in EHRs. 


\subsection{Objective}

To provide a systematic review of peer-reviewed literature about the ICF's use in EHRs, including related challenges and benefits.

\section{Methods}

Employing the Preferred Reporting Items for Systematic Reviews and Meta-Analyses (PRISMA) method [21] we performed a systematic literature review to identify international, peer-reviewed publications that have examined the use of the ICF in EHRs. The PRISMA Checklist can be found in Online Appendix 1. The process involved five steps: literature search, publication selection, quality assessment, information extraction and descriptive synthesis of results.

\subsection{Literature search}

We searched in four literature databases: Medline ${ }^{\oplus}$, CINAHL $^{\oplus}$, Scopus ${ }^{\oplus}$, and ProQuest ${ }^{\oplus}$ Social Sciences. The query was developed in a query definition process resulting in the search terms ICF AND (Electronic Health Records OR Documentation OR Information Management System). - Table 1 displays a summary of respective synonyms and subjects headings that were used. The search encompassed the period from January 2001, the year when the ICF was released, to June 2015 (final search 23 July 2015). Online Appendix 2 contains more detailed information about the search.

We handled the references with the reference management software EndNote ${ }^{\varpi}$. Duplicates were removed once abstracts were identified from all databases.

\subsection{Publication selection}

We screened titles and abstracts considering the eligibility criteria listed in $>$ Table 2 . Publications were only included when the ICF was explicitly described as an integral part of EHR. For example publications that only used the ICF as a tool to analyze the content of EHRs retrospectively were excluded. Excel $^{\otimes}$ spreadsheets were used to document the screening process. If the title and abstract of a publication did not provide sufficient information to decide whether the article should be included, we included the publication for full text screening. The full texts of the identified publications were obtained, and the eligibility criteria applied again. To ensure reliability of the inclusion procedure, two researchers (RM, CW) independently screened the first $10 \%$ of identified publications. If agreement was $>90 \%$ then one reviewer continued the screening process alone. If agreement was $\leq 90 \%$ the two reviewers continued the screening independently. A third reviewer (BP) was involved in cases of disagreement or uncertainty.

\subsection{Quality assessment of included publications}

In our review the quality assessment was not relevant for the publication selection, but used as a tool to better describe the articles that were included. Specific quality criteria have been developed for this review adapted by the ICF literature review of Maribo et al. [11] referring to the use of the conceptual model underpinning the ICF, and its classification framework. If the full ICF conceptual model is used, all components of the ICF (Health Condition, Body Structure, Body Function, Activities and Participation, Environmental Factors and Personal Factors) should be documented. ICF codes are the unit of the classification. ICF codes consist of a textual definition and a qualifier, which specifies numerically the extent of problems experienced in a given functioning category [22]. Thus, for the classification framework to be considered as fully used, ICF codes and the related qualifiers would need to be recorded. 


\subsection{Information extraction and descriptive synthesis of results}

Information extraction occurred in two steps. First, publication characteristics, including year, author, title, region, and clinical setting were extracted. The publications were categorized into three groups representing the entire implementation process:

- Requirement specification: publications on conceptual considerations about the design and use of the ICF in EHRs;

- Development: publications on technical development of EHRs in which the ICF was used; and

- Implementation: publications which examine actual projects concerning the use of ICF in EHRs in clinical practice.

The groups have been adapted according to the groups outlined in the ICF literature review of Cerniauskaite et al. [10] so that they can be compared to previous ICF reviews, and to the evaluation framework for health information system of Kaufman et al. [23] to reflect the specialised field of health information systems.

Second, a qualitative content analysis [24, 25] was conducted to synthesize the information. The content analysis included four stages: coding, grouping, categorization, and data abstraction. The categorization phase was deductively oriented at the evaluation framework for health information systems (HOT-fit) [26]. The HOT-fit framework addresses the Human, including system use and user satisfaction, the Organization, including structure and environment, the Technology, including information quality, system quality and service quality, and the Net Benefits, including benefits and challenges of any information system. In the present review Net Benefits refer to barriers and facilitators of ICF use in EHRs. The HOT-fit framework builds upon knowledge based on health and information sciences [27] and has been recommended and recently used for evaluation of health information systems [28-32]. Information relevant to the use of the ICF in an EHR system was extracted and categorized according to the HOT-fit framework using an Excel ${ }^{\circledR}$ spreadsheet. Decisions for or against certain characteristics in the system under study, e.g. selecting the ICF over another terminology, were assigned to benefits and challenges, even if they were not explicitly stated as such.

\subsection{Content validation from a group of ICF experts}

We presented and discussed the study protocol and obtained results with members of the ICF Research Branch, a partner within the WHO Collaborating Centre for the Family of International Classifications in Germany, at two expert meetings in Nottwil, Switzerland, in June and July 2015. The ICF Research Branch has substantial domain expertise in the development, evaluation and dissemination of ICF-based tools [33].

\section{Results}

\subsection{Literature search}

After the removal of duplicates, 325 publications were identified through the electronic literature search. The rater agreement of the first $10 \%$ screening sample was $94 \%$ (31 of 33); consequently, one researcher $(\mathrm{RM})$ conducted the remaining screening.

\subsection{Publication selection}

Based on the title and abstract screening the full texts of 45 publications were obtained. Of these, 15 publications met the eligibility criteria. Online Appendix 3 displays a flow diagram of the literature search and Online Appendix 4 lists the reasons for excluding articles. In addition to the database search, two additional articles were identified. One was identified through a conference proceedings, revealed in the literature search. A follow-up publication of this conference proceeding that provided more detailed information on the EHR project was found and replaced the original publi- 
cation. The other one was a publication found during the search for literature published by a research group named during the ICF expert meeting. Consequently, 17 articles were included [34-50].

\subsection{Quality assessment of included publications}

- Table 3 presents a detailed overview of the components addressed in each publication. The use of all ICF components was reported in 6 out of the 17 publications. References to the ICF component "Activities and Participation“ were seen in all publications, to „Body Functions“ in 16 publications, to „Environmental Factors" in 14 publications, and to „Body Structures" and „Health Condition“ each in 13 publications. Only 7 publications referred to "Personal Factors". The application of the classification framework, including ICF codes and qualifiers, was reported in 8 publications. In 5 publications there was no explicit reference to the use of ICF qualifiers in the text, but it appeared as if they were used according to the figures and tables presented in the publication. In 4 the use of ICF qualifiers was not mentioned.

\subsection{Data extraction and synthesis of results}

\subsubsection{Publication characteristics}

Table 4 provides a detailed overview of the publication characteristics. Beside the 13 publications in English, 3 German, and 1 Spanish language publication were included. Most publications came from Europe followed by North America. The ICF has been used in EHRs in a variety of settings, including rehabilitation, general healthcare, and in profession-specific records. Out of the 17 identified publications, 4 referred to requirement specifications, 7 to development, and 6 to implementation. Two implementation publications $[48,50]$ described the same project.

\subsubsection{Information according to the HOT-fit evaluation framework}

The synthesis of the results of the qualitative content analysis is presented according to the four aspects of the HOT-fit framework - Technology, Human, Organization, and Net Benefits [26].

\section{Technology}

Themes that emerged with respect to Technology are grouped in line with the HOT-fit framework, i.e. into Information Quality, System Quality and Service Quality. A comprehensive overview of themes and examples are provided in $>$ Table 5, grouped according to the publication group.

Information Quality: Across publications, it was highlighted that the comprehensiveness and focus of the ICF's conceptual model allow going beyond a purely medical perspective towards a biopsycho-social understanding of health [34-37, 39-50]. The universal and interdisciplinary language of the ICF, which can be applied in different healthcare settings, by different professions, and across countries, was also highlighted as a benefit of using the ICF [34, 35, 39, 41, 43-46, 48, 50]. Another theme that emerged across publications was the use of the ICF, including the codes and qualifiers $[34,36,38,39,41,43,44,47,49]$, as a means to standardize health information. Such a standardization fosters interoperability and comparability across information systems, and ultimately strengthens data quality. Though the comprehensiveness was stated as a strength of the ICF, the majority of publications also pointed out the necessity of selecting a reduced number of ICF codes for the ICF to be feasible for coding in clinical practice [36-45, 47-50]. Various approaches to reducing or selecting codes were suggested, such as automated code selection through natural language processing [34, 37, 40, 45].

System Quality: Some of the themes that emerged with respect to system quality were more general, others were specific to the ICF. The general themes referred to the necessity of implementing and ensuring compatibility of various information standards [34, 36-38, 44, 46, 49] and to data safety considerations [36, 38, 42-44, 49]. Examples include authorization for information access [36, $42,44]$, or the requirements for a database environment $[35,36,38,41-43,48,50]$ that can be used to visualize and represent meaningful information to patients in the clinical encounter $[36,37,39$, $41,43,46]$. The themes specific to the ICF refer to its shortcomings as a formal EHR compatible ter- 
minology and its lack of an ontology. Both themes challenge the development of a machine-readable knowledge system $[35,36]$.

Service Quality: Limited reference was given to Service Quality in the identified papers. Three publications referred to the internal IT services that technically supported the implementation of the ICF in EHRs [37, 38, 42], e.g. outlining how expenditures were kept low through the implementation of new features in EHRs [42].

\section{Human}

Themes that emerged regarding the Human are grouped into System Use and User Satisfaction, summarized in $>$ Table 6 , grouped according to the different publication groups.

System Use: The multidisciplinary healthcare team was described as main and active user [35-37, 39-48, 50] across publications. Passive users, such as patients, administrators and insurances, were mentioned as profiting from the information captured in the EHR, but do not enter nor change the data within the system $[36,39,42,47,48,50]$. These roles depend on the purpose and context in which an information system is used. For example, one publication described how the EHR was integrated into a social network where the patient becomes an active user [36]. Another publication identified students in healthcare professions as users of EHRs, specifically for educational purposes [41]. Across publications the importance of training users on the respective ICF-based system was emphasized as a necessary investment to make $[34,35,37-40,44-48,50]$ to ensure that users understand the ICF's content and structure.

User Satisfaction: Only publications categorized into the group of implementation contained information about User Satisfaction. Across most publications, positive aspects, such as high motivation of users to use the ICF, good user acceptance, as well as the continuous user involvement in the entire process - from requirement specification to implementation were highlighted. In one publication users perceived the information load as too burdensome, and in particular older users reported problems [36].

\section{Organization}

Aspects according to the HOT-fit category Organization were only found in publications related to implementation. They are summarized in $>$ Table 7.

Organizational Structure: This factor refers to healthcare institutions, where the ICF was used in EHR. Mainly rehabilitation settings were identified. The publications mentioned that the ICF meets the modern definition of rehabilitation, and in particular its suitability for the description of complex patients $[39,48,50]$.

Organizational Environment: The environment was only described in two publications [42, 44], in which the influence of payers and national legislations were addressed.

\section{Net Benefits}

- Table 8 summarizes the benefits and challenges in using the ICF in EHRs.

Benefits: Themes that were described across the publication groups were the positive effects of the ICF's comprehensiveness, including the corresponding information [34-37, 39-50] and the standardization enabled by the ICF $[35,36,39,41,43-50]$. These ICF properties facilitates, among other things, clinical decision making [34, 37, 39, 48-50]. These aspects can subsequently lead to quality improvement in the clinical process, reporting and multidisciplinary collaboration [39, 42, 48-50] through the transfer of information and knowledge.

Challenges: One frequently identified challenge was the difficulty to achieve interoperability [34-36, 41, 46, 49]. In the analyzed publications there are calls for action for adopting the ICF to promote interoperability. As in the evaluation factor Technology, the selection of a reduced number of ICF categories to a practical set was mentioned as a challenge [36, 37, 40, 45, 47-50]. An additional challenge is the time-intensiveness of the process to implement the ICF in EHRs $[45,48,50]$. This factor, however, seemed to be balanced by the time efficiency reached in other clinical processes [34, 37, 40, 42, 45]. Among the publications on implementation, the challenges identified, e.g. the lack of specificity, were reported in the light of the technical solution, e.g. natural language processing that was chosen in the respective study. Moreover, practice-related challenges were also re- 
vealed, e.g. two projects refrained from using qualifiers, as they were viewed as too impractical to use $[44,48,50]$.

\section{Discussion}

\subsection{Findings}

The objective of this systematic review was to examine the current state of peer-reviewed literature on the efforts toward implementing the ICF in EHR, including related challenges and benefits. The review revealed various past and current initiatives toward implementing the ICF in EHRs across the globe [34-50]. The review demonstrates that the use of the ICF has been documented in different clinical settings, predominately in rehabilitation settings. The more extensive presence in rehabilitation is understandable as rehabilitation aims to optimize functioning and prevent disability [51]. Rehabilitation was also one of the settings most frequently mentioned in other reviews about the use of the ICF $[10,11]$. The three groups, i.e. requirement specification, development and implementation research, reflect the entire implementation process. This process starts from arguing why the use of the ICF in EHRs is important in the publications related to requirement specification, to the actual development of technical solutions, and subsequent implementation. The findings related to each of the groups are relevant for different stakeholders. Publications related to requirement specification provide a theoretical background that can be used for research and education. The knowledge gained from publications on development provide an overview about different technical solutions as well as highlight practical implications that are important for the clinical context. Although this review provides evidence that the ICF is a recognized standard, evidence on its implementation in clinical practice is evolving slowly. Implementing the ICF in practice requires its integration into a system that is likely already saturated with various standards and routines. Thus, the process until any new standard, such as the ICF, is implemented is time- and resource-intensive [52].

\subsection{Relevant challenges and benefits of the ICF's use in EHRs}

In this review, the comprehensiveness and universal applicability of the ICF was referred to as a major benefit of the ICF. A second benefit was the support of interdisciplinary collaboration, for example toward quality improvement $[48,50]$. A third benefit of using the ICF in EHR system identified in the publications was the high user satisfaction where ICF was actually implemented.

The most common challenge identified in this review pointed to the need for further work on enhancing the ICF's potential in enabling interoperability. This is also supported by other related literature [53]. One step toward addressing this issue has started with the initiative to explore possibilities of developing an ICF ontology and linking the ICF with clinical terminologies (e.g. SNOMED-CT) [54]. Once such an ontology is available, coordinated efforts by relevant stakeholders in health systems are needed to develop tools that guide and facilitate the implementation of ICF in EHR. Another challenge of using the ICF in EHRs, revealed in this review was its distinction from existing medical terminologies, given its comprehensive perspective on health. Facing this challenge necessitates a paradigm shift towards a more holistic bio-psycho-social perspective of health. Furthermore, training professionals according to this perspective is required. Tools for ICF user training exist, e.g. WHO's ICF Practical Manual [22], WHO’s ICF e-learning tool [55], and ICF-based case studies [56]. Moreover, the findings of this review indicate that the complexity of the ICF represents a major problem. It remains challenging to reduce or choose the most relevant ICF codes for a given setting in a meaningful way. If every hospital or clinic employs their own methods for selecting codes, it would pose a major barrier to achieve information comparability. Therefore, this issue needs to be considered when creating or using a production EHR system. Solutions about how to select a reduced number of codes were proposed in the included publications [34, 36, 37, 39-41, 43-45, 48, 50], for example through natural language processing [34, 37, 40, 45]. Other approaches for establishing a practical selection of codes includethe multi-stage, mixed method process to develop internationally-applicable ICF Core Sets [57] and the process to develop standard chapter headings for EHRs for people with long-term conditions [19]. 
The analysis in this review also revealed the need of further research to gather evidence the application and added value of using ICF. Maribo et al. [11] concluded that there is still a long way to go before the ICF is widely used in rehabilitation and other clinical settings. Based on the findings of this review, which focused specifically on the use of the ICF in EHRs, we see a more positive trend in the uptake of the ICF. Though many technical challenges have been identified, there was general agreement across reviewed papers that the ICF provides a valuable framework for use in clinical practice.

Though the findings of this review refer mainly to healthcare and related professionals, it is important that other stakeholders involved in any building block of a health system, including governance and financing, are made aware of the value of a comprehensive perspective on health, as reflected in the ICF, to gather additional support for ICF implementation in EHR [58].

\subsection{Limitations of the study}

A main limitation of the review is the small number of publications included. This might be due to the fact that many projects aiming to implement the ICF in EHRs are not reported in peer-reviewed literature, i.e. the review may not be representative of all existing ICF implementation efforts. However, this systematic literature review represents a first step toward gaining evidence on the use of the ICF in EHRs. These findings need to be complemented in the future with other methods, such as surveys among healthcare institutions.

A second limitation is the high number of excluded publications. This may be due to the broad search terms we chose to avoid missing any relevant publications. On the other hand, our search terms did not cover all the relevant articles, as two articles have been identified in our additional search. We analyzed the MeSH terms of these publications and found them to be even broader - one [39] with the major topic MeSH terms Disability Evaluation, International Classification of Diseases/standards, Outcome Assessment (Health Care)/methods, Software/standards, Spinal Cord Injuries/rehabilitation, the other [45] with Activities of Daily Living/classification, Forms and Records Control, Natural Language Processing, Patient Discharge. A further limitation of the review is publication bias; the six publications describing the actual implementation of the ICF in EHR in clinical practice were all successful examples of the use of the ICF. Unsuccessful examples of implementation are probably not published. Furthermore, it has to be stated that two publications $[43,44]$ seemed to market a particular software product. These publications may present their findings in a potentially biased way. Despite inter-rater agreement in the first 10\% of the screened abstracts was good with $94 \%$, there still might be some bias in the overall abstract screening. To partly address this possible bias, in cases of ambiguity, abstracts were included for full text screening to prevent the exclusion of relevant publications.

\subsection{Conclusion}

This systematic literature review outlines different approaches and technical solutions to integrate the ICF in EHRs, such as combining the ICF with other existing standards for EHRs or selecting ICF codes with natural language processing. The findings point to benefits in using the ICF in EHRs, such as its comprehensiveness and its interdisciplinary focus. Additionally, user satisfaction was reported to be high once implementation was successful. The need for further work on developing a formal EHR-compatible terminology or ontology of functioning has been pointed out as a way to enhance interoperability.

\subsection{Clinical relevance}

The underlying review provides a summary of existing peer-reviewed literature representing ideas and solutions how the ICF can be implemented in EHRs. Main benefits of implementing the ICF: its unique perspective and its interdisciplinary focus. Main challenges of implementing the ICF in EHRs: the ICF is not structured as a formal EHR-compatible terminology, and meaningfully selecting a reduced number of the ICF codes for daily use. 


\section{Multiple Choice Question}

What approaches have been described in the current literature review to select or reduce the number of ICF codes for use in electronic health records?

A) Patient selection, systematic review driven selection, and selection of codes with lowest levels

B) Random selection, purposive selection, and selection of codes that have an association to other codes

C) In none of the included papers there was a selection or reduction of the ICF codes

D) Expert selection, mapping of existing assessment or data sets, and automatic selection

Answer D is correct. In $>$ Table 5 you can see that the included publications describe the necessity of selecting a reduced number of ICF codes [34, 36-45, 47-50] as the classification with over 1400 codes is very extensive and impractical for daily use. Various approaches for reduction have been applied: expert selection $[39,41,48,50]$, mapping of existing assessments or data sets to the ICF [43, $44]$, or automatic selection $[34,36,37,40,45]$. One aspect of automatic selection that was described was the possibility to generate automatically-selected ICF codes through natural language processing $[34,37,40,45]$.

\section{Acknowledgements}

The authors would like to acknowledge the support of Chelsey Weleschuk in assisting with the protocol development and paper screening, Núria Duran Adroher for her support with the Spanish publication, and Melissa Selb for language proofreading.

\section{Conflicts of Interest}

The authors declare that they have no conflicts of interest in this research.

\section{Protection of Human an Animal subjects}

This project did not involve human and/or animal subjects. 
Table 1 Search strategy: Search terms, synonyms and subject headings

\begin{tabular}{|c|c|c|}
\hline Search Terms & $\begin{array}{l}\text { Synonyms, subsumed terms, generic } \\
\text { terms }\end{array}$ & Subject headings \\
\hline ICF & $\begin{array}{l}\text { International Classification of Functioning, } \\
\text { Disability and Health }\end{array}$ & $\begin{array}{l}\text { "International Classification of Functioning, } \\
\text { Disability and Health" }\end{array}$ \\
\hline $\begin{array}{l}\text { Electronic health } \\
\text { records }\end{array}$ & $\begin{array}{l}\text { Health records, patient records, medical rec- } \\
\text { ords, hospital records }\end{array}$ & $\begin{array}{l}\text { "Electronic health record", "Medical Rec- } \\
\text { ords", "Hospital Records" }\end{array}$ \\
\hline Documentation & Documenting & "Documentation" \\
\hline $\begin{array}{l}\text { Information } \\
\text { Management } \\
\text { System }\end{array}$ & $\begin{array}{l}\text { Information System, Document management } \\
\text { system }\end{array}$ & $\begin{array}{l}\text { "Information Systems", "Information Man- } \\
\text { agement", "Patient record systems", " medi- } \\
\text { cal record system, computerized", " com- } \\
\text { puterized patient record" "patient record sys- } \\
\text { tems" }\end{array}$ \\
\hline
\end{tabular}

Table 2 Eligibility criteria

\begin{tabular}{l|l}
\hline Inclusion criteria & Exclusion criteria \\
\hline $\begin{array}{l}\text { - Explicit reference to the use of the ICF in EHR, including require- } \\
\text { ment specification and design, development and testing, and im- }\end{array}$ & $\begin{array}{l}\text { ICF was used for analysis of data retriev- } \\
\text { ed from EHRs but ICF was not integrated } \\
\text { plementation }\end{array}$ \\
$\begin{array}{l}\text { - No restrictions in study design } \\
\text { - Records used and produced outside } \\
\text { - Publications published between January 2001, the year of the }\end{array}$ & $\begin{array}{l}\text { healthcare institutions, such as popu- } \\
\text { lation records or records in special edu- } \\
\text { cation }\end{array}$ \\
$\begin{array}{l}\text { ICF's release [13], and June } 2015 \\
\text { - Abstracts available in English language; full texts available in } \\
\text { either German, English, French or Spanish language (Note: differ- } \\
\text { ent research team members were fluent in these languages) }\end{array}$ &
\end{tabular}

Table 3 Quality Assessment; Legend: $\checkmark$ = identified in the text; = interpreted from the text or figures but not explicitly stated in the text; $x=$ not reported in the text, in tables or figures; $\mathrm{HC}=$ Health Condition, $\mathrm{BF}=$ Body Functions, $\mathrm{BS}=$ Body Structures, A\&P = Activities and Participation, EF = Environmental Factors, PF $=$ Personal Factors

\begin{tabular}{|c|c|c|c|c|c|c|c|c|c|c|c|c|}
\hline Author & Year & Group & $\begin{array}{l}\text { ICF Frame- } \\
\text { work }\end{array}$ & & & & & & & $\begin{array}{l}\text { ICF } \\
\text { Codes }\end{array}$ & $\begin{array}{l}\text { ICF Quali- } \\
\text { fiers }\end{array}$ & $\begin{array}{l}\text { Refer- } \\
\text { ence }\end{array}$ \\
\hline & & & & $\mathrm{HC}$ & BF & BS & $A \& P$ & EF & PF & & & \\
\hline Vreeman, Richoz & 2013 & $\begin{array}{l}\text { Requirement } \\
\text { Specification }\end{array}$ & $\checkmark$ & $\checkmark$ & $\checkmark$ & $\checkmark$ & $\checkmark$ & $\checkmark$ & $\checkmark$ & $\checkmark$ & $\checkmark$ & [34] \\
\hline $\begin{array}{l}\text { Tanaka, Matsu- } \\
\text { moto }\end{array}$ & 2013 & Development & $\checkmark$ & $\checkmark$ & $\checkmark$ & $\checkmark$ & $\checkmark$ & $\checkmark$ & $\checkmark$ & $\checkmark$ & $\checkmark$ & [35] \\
\hline Subirats et al. & 2013 & $\begin{array}{l}\text { Implemen- } \\
\text { tation }\end{array}$ & $\checkmark$ & $\checkmark$ & $\checkmark$ & $x$ & $\checkmark$ & $\checkmark$ & $\checkmark$ & $\checkmark$ & $\sim$ & [36] \\
\hline Frattura et al. & 2012 & Development & $\checkmark$ & $\checkmark$ & $\checkmark$ & $\checkmark$ & $\checkmark$ & $\checkmark$ & $\checkmark$ & $\checkmark$ & $x$ & [37] \\
\hline Della Mea, Fioresi & 2012 & Development & $x$ & $\checkmark$ & $\checkmark$ & $\checkmark$ & $\checkmark$ & $\checkmark$ & $x$ & $\checkmark$ & $\sim$ & [38] \\
\hline $\begin{array}{l}\text { Spreyermann et } \\
\text { al. }\end{array}$ & 2011 & $\begin{array}{l}\text { Implemen- } \\
\text { tation }\end{array}$ & $\checkmark$ & $\checkmark$ & $\checkmark$ & $x$ & $\checkmark$ & $\checkmark$ & $x$ & $\checkmark$ & $\checkmark$ & [39] \\
\hline Manabe et al. & 2011 & Development & $\checkmark$ & $\checkmark$ & $\checkmark$ & $\checkmark$ & $\checkmark$ & $\checkmark$ & $x$ & $\checkmark$ & $\checkmark$ & [40] \\
\hline $\begin{array}{l}\text { Martínez, Sán- } \\
\text { chez }\end{array}$ & 2010 & Development & $\sim$ & $\checkmark$ & $\checkmark$ & $\checkmark$ & $\checkmark$ & $\checkmark$ & $x$ & $\checkmark$ & $\checkmark$ & [41] \\
\hline $\begin{array}{l}\text { Kalwa, } \\
\text { Greitemann }\end{array}$ & 2009 & $\begin{array}{l}\text { Implemen- } \\
\text { tation }\end{array}$ & $\checkmark$ & $\checkmark$ & $\checkmark$ & $\checkmark$ & $\checkmark$ & $\checkmark$ & $x$ & $\checkmark$ & $x$ & [42] \\
\hline Lehnguth, Leidag & 2007 & Development & $x$ & $x$ & $\sim$ & $x$ & $\checkmark$ & $x$ & $x$ & $\sim$ & $\sim$ & [43] \\
\hline
\end{tabular}


Table 3 Continued

\begin{tabular}{|c|c|c|c|c|c|c|c|c|c|c|c|c|}
\hline Author & Year & Group & $\begin{array}{l}\text { ICF Frame- } \\
\text { work }\end{array}$ & & & & & & & $\begin{array}{l}\text { ICF } \\
\text { Codes }\end{array}$ & $\begin{array}{l}\text { ICF Quali- } \\
\text { fiers }\end{array}$ & $\begin{array}{l}\text { Refer- } \\
\text { ence }\end{array}$ \\
\hline & & & & $\mathrm{HC}$ & BF & BS & A\&P & EF & PF & & & \\
\hline $\begin{array}{l}\text { Van Grunsven et } \\
\text { al. }\end{array}$ & 2006 & $\begin{array}{l}\text { Implemen- } \\
\text { tation }\end{array}$ & $x$ & $x$ & $\checkmark$ & $\checkmark$ & $\checkmark$ & $x$ & $x$ & $\sim$ & $\sim$ & {$[44]$} \\
\hline Kukafka et al. & 2006 & Development & $\checkmark$ & $x$ & $\checkmark$ & $x$ & $\checkmark$ & $x$ & $x$ & $\checkmark$ & $\checkmark$ & {$[45]$} \\
\hline $\begin{array}{l}\text { Giannangelo et } \\
\text { al. }\end{array}$ & 2005 & $\begin{array}{l}\text { Requirement } \\
\text { Specification }\end{array}$ & $\checkmark$ & $\checkmark$ & $\checkmark$ & $\checkmark$ & $\checkmark$ & $\checkmark$ & $x$ & $\checkmark$ & $\sim$ & {$[46]$} \\
\hline Üstün et al. & 2003 & $\begin{array}{l}\text { Requirements } \\
\text { Specification }\end{array}$ & $\checkmark$ & $\checkmark$ & $\checkmark$ & $\checkmark$ & $\checkmark$ & $\checkmark$ & $\checkmark$ & $\checkmark$ & $\checkmark$ & [47] \\
\hline Rentsch et al. & 2003 & $\begin{array}{l}\text { Implemen- } \\
\text { tation }\end{array}$ & $\sim$ & $\checkmark$ & $\checkmark$ & $\checkmark$ & $\checkmark$ & $\checkmark$ & $\checkmark$ & $\checkmark$ & $x$ & [48] \\
\hline Harris et al. & 2003 & $\begin{array}{l}\text { Requirement } \\
\text { Specification }\end{array}$ & $\checkmark$ & $x$ & $\checkmark$ & $\checkmark$ & $\checkmark$ & $\checkmark$ & $x$ & $\checkmark$ & $\checkmark$ & [49] \\
\hline Rentsch et al. & 2001 & $\begin{array}{l}\text { Implemen- } \\
\text { tation }\end{array}$ & $\sim$ & $\checkmark$ & $\checkmark$ & $\checkmark$ & $\checkmark$ & $\checkmark$ & $\checkmark$ & $\checkmark$ & $x$ & {$[50]$} \\
\hline
\end{tabular}

Table 4 Publication characteristics ordered by group

\begin{tabular}{|c|c|c|c|c|c|c|}
\hline Author & Year & Group & Language & Region & Clinical Setting & $\begin{array}{l}\text { Refer- } \\
\text { ence }\end{array}$ \\
\hline Vreeman, Richoz & 2013 & $\begin{array}{l}\text { Requirement } \\
\text { Specification }\end{array}$ & English & $\begin{array}{l}\text { North America } \\
\text { (United States) } \\
\text { and Oceania } \\
\text { (Australia) }\end{array}$ & Physiotherapy & [34] \\
\hline $\begin{array}{l}\text { Giannangelo et } \\
\text { al. }\end{array}$ & 2005 & $\begin{array}{l}\text { Requirement } \\
\text { Specification }\end{array}$ & English & $\begin{array}{l}\text { North America } \\
\text { (United States) }\end{array}$ & $\begin{array}{l}\text { General healthcare } \\
\text { setting }\end{array}$ & [46] \\
\hline Üstün et al. & 2003 & $\begin{array}{l}\text { Requirement } \\
\text { Specification }\end{array}$ & English & $\begin{array}{l}\text { Europe (Switzer- } \\
\text { land) and North } \\
\text { America (Cana- } \\
\text { da) }\end{array}$ & $\begin{array}{l}\text { General healthcare } \\
\text { setting }\end{array}$ & [47] \\
\hline Harris et al. & 2003 & $\begin{array}{l}\text { Requirement } \\
\text { Specification }\end{array}$ & English & $\begin{array}{l}\text { North America } \\
\text { (United States) }\end{array}$ & $\begin{array}{l}\text { General healthcare } \\
\text { setting }\end{array}$ & [49] \\
\hline $\begin{array}{l}\text { Tanaka, } \\
\text { Matsumoto }\end{array}$ & 2013 & Development & English & Asia (Japan) & Not defined & [35] \\
\hline Frattura et al. & 2012 & Development & English & Europe (Italy) & $\begin{array}{l}\text { Tested in outpatients } \\
\text { care }\end{array}$ & [37] \\
\hline $\begin{array}{l}\text { Della Mea, } \\
\text { Fioresi }\end{array}$ & 2012 & Development & English & Europe (Italy) & Not defined & [38] \\
\hline Manabe et al. & 2011 & Development & English & Asia (Japan) & $\begin{array}{l}\text { Domiciliary mental } \\
\text { healthcare }\end{array}$ & [40] \\
\hline $\begin{array}{l}\text { Martínez, } \\
\text { Sánchez }\end{array}$ & 2010 & Development & Spanish & $\begin{array}{l}\text { South America } \\
\text { (Colombia) }\end{array}$ & Rehabilitation & [41] \\
\hline Lehnguth, Leidag & 2007 & Development & German & $\begin{array}{l}\text { Europe } \\
\text { (Germany) }\end{array}$ & $\begin{array}{l}\text { Adult rehabilitation, } \\
\text { occupational therapy } \\
\text { setting }\end{array}$ & [43] \\
\hline Kukafka et al. & 2006 & Development & English & $\begin{array}{l}\text { North America } \\
\text { (United States) }\end{array}$ & $\begin{array}{l}\text { Inpatient rehabili- } \\
\text { tation }\end{array}$ & [45] \\
\hline
\end{tabular}


Table 4 Continued

\begin{tabular}{|c|c|c|c|c|c|c|}
\hline Author & Year & Group & Language & Region & Clinical Setting & $\begin{array}{l}\text { Refer- } \\
\text { ence }\end{array}$ \\
\hline Subirats et al. & 2013 & Implementation & English & Europe (Spain) & Rehabilitation & [36] \\
\hline $\begin{array}{l}\text { Spreyermann et } \\
\text { al. }\end{array}$ & 2011 & Implementation & English & $\begin{array}{l}\text { Europe } \\
\text { (Switzerland) }\end{array}$ & $\begin{array}{l}\text { Spinal cord injury out- } \\
\text { patient setting }\end{array}$ & [39] \\
\hline $\begin{array}{l}\text { Kalwa, Greite- } \\
\text { mann }\end{array}$ & 2009 & Implementation & German & $\begin{array}{l}\text { Europe } \\
\text { (Germany) }\end{array}$ & Rehabilitation clinic & [42] \\
\hline $\begin{array}{l}\text { Van Grunsven et } \\
\text { al. }\end{array}$ & 2006 & Implementation & English & $\begin{array}{l}\text { Europe } \\
\text { (Netherlands) }\end{array}$ & $\begin{array}{l}\text { Hospital, neurological } \\
\text { ward }\end{array}$ & [44] \\
\hline Rentsch et al. & 2003 & Implementation & English & $\begin{array}{l}\text { Europe } \\
\text { (Switzerland) }\end{array}$ & $\begin{array}{l}\text { Neuro-rehabilitation } \\
\text { inpatient unit }\end{array}$ & [48] \\
\hline Rentsch et al. & 2001 & Implementation & German & $\begin{array}{l}\text { Europe } \\
\text { (Switzerland) }\end{array}$ & $\begin{array}{l}\text { Neuro-rehabilitation } \\
\text { inpatient unit }\end{array}$ & [50] \\
\hline
\end{tabular}

Table 5 Technology attributes of the HOT-fit evaluation framework; CEN 1828: Health Informatics - Categorical Structure for Classifications and Coding Systems of Surgical Procedures, ClaML: Classification Markup Language, EN 13606: Health informatics - Electronic Health Record Communication, HL7: Health Level Seven, ICD:International Classification of Diseases, ICF CY: International Classification of Functioning, Disability and Health for Children and Youth, ISO9999-1998: Technical aids for disabled persons - Classification, IT: Information Technology, LOINC: Logical Observation Identifiers Names and Codes, SNOMED CT: Systematized Nomenclature of Human and Veterinary Medicine Clinical Terms

\begin{tabular}{|c|c|c|}
\hline Group & Information Quality & System Quality \\
\hline Across groups & $\begin{array}{l}\text { - Comprehensiveness and focus of conceptual model } \\
\text { underpinning the ICF which goes beyond the pure } \\
\text { medical understanding of health towards a bio-psy- } \\
\text { cho-social understanding [34-37, 39-50] } \\
\text { Standardization through ICF in its function as classifi- } \\
\text { cation [35, 36, 39, 41, 43-50] } \\
\text { - Universal and interdisciplinary nature of the ICF lan- } \\
\text { guage [34, 35, 39, 41, 43-46, 48, 50], it facilitates in } \\
\text { particular to communicate different professional per- } \\
\text { spectives [34, 43, 46] } \\
\text { Data structured according the ICF is useful for further } \\
\text { applications: clinical decision making [34, 37, 39, } \\
48-50], \text { evaluation [34, 36, 37, 42, 47-50], research } \\
\text { [36, 37, 41, 45, 48, 50], patient management and } \\
\text { treatment process [34, 37, 42, 43, 45, 46, 48, 50] } \\
\text { Application of ICF codes and the corresponding quali- } \\
\text { fiers was recommended [34, 36, 38, 39, 41, 44, 45, 47, } \\
49] . \text { Possibility of having generic and advanced quali- } \\
\text { fiers (capacity and performance) was acknowledged } \\
\text { [44, 47] } \\
\text { Necessity of reduction or selection of ICF codes pro- } \\
\text { posed [34, 36-45, 47-50] as the classification with } \\
\text { over } 1400 \text { codes is very extensive. Various approaches } \\
\text { for reduction have been applied: expert selection [39, } \\
41,48,50] \text {, mapping of existing assessments or data } \\
\text { sets to the ICF [43, 44], or automatic selection [34, } \\
36,37,40,45]\end{array}$ & $\begin{array}{l}\text { - Combination of the ICF with different other standards such as: } \\
\text { HL7[34, 36, 37, 44, 49], ClaML [37, 38], SNOMED CT [34, 36], } \\
\text { LOINC [34], EN 13606 [36], ICD[37] ICF-CY [37], ISO9999-1998 } \\
\text { [37], and CEN } 1828 \text { [44] } \\
\text { - Data safety is important to be considered when changes are } \\
\text { made in an EHR system [36, 38, 42-44, 49] } \\
\text { - Code selection: Generation of automatically selected ICF codes is } \\
\text { possible through natural language processing [34, 37, 40, 45] } \\
\text { - Need for an ontology to represent information within the health } \\
\text { information system when using the ICF in EHRs [35, 36] } \\
\text { - A database [35, 36, 38, 41-43, 48, 50] and the visual presenta- } \\
\text { tion or transformation of such ICF based information [36, 37, 39, } \\
\text { 41, 43, 46] are important system features } \\
\text { Web-based applications were used for the use of the ICF in EHRs } \\
\text { [36-38, 44] } \\
\text { Service Quality refers to: } \\
\text { - Internal IT-Department can cover service to implement the ICF in } \\
\text { EHRs [37, 38, 42]. This can lead to no additional expenditure for } \\
\text { service [42] }\end{array}$ \\
\hline $\begin{array}{l}\text { Requirements } \\
\text { Spec. }\end{array}$ & No additional information & No additional information \\
\hline
\end{tabular}


Table 5 Continued

\begin{tabular}{|c|c|c|}
\hline Group & Information Quality & System Quality \\
\hline Development & No additional information & $\begin{array}{l}\text { Five different approaches were described: } \\
\text { - Reorganization of the ICF to get a functional ontology [35] } \\
\text { - Translation of the information into ICF codes with a Natural Lan- } \\
\text { guage Processing program }[37,40,45] \\
\text { - Information can then be combined with different standards [37], } \\
\text { or completed with a search system that facilitates code selec- } \\
\text { tion[40] } \\
\text { - The ICF can be used to structure data in an intern EHR that is not } \\
\text { interoperable with other systems [41, 43] } \\
\text { ICF sub-sets can be translated into ClaML, to get an implemen- } \\
\text { tation profile that can be integrated in the existing information } \\
\text { system [38] }\end{array}$ \\
\hline $\begin{array}{l}\text { Implemen- } \\
\text { tation }\end{array}$ & $\begin{array}{l}\text { In two projects the ICF qualifiers, that rate the magni- } \\
\text { tude of a problem were not used, they were replaced by } \\
\text { ICF coded goals or assessments }[42,48,50]\end{array}$ & $\begin{array}{l}\text { Three different approaches were described: } \\
\text { - The information system can be used like social network platform, } \\
\text { where also the patient has access [36] } \\
\text { - ICF data sets can be implemented in the EHR system, where as- } \\
\text { sessment or minimal dataset are entered }[39,44,48,50] \\
\text { - Rehabilitation goals can be coded through a database mask. On } \\
\text { this basis automatic generated reports can be produced using a } \\
\text { template generator [42] }\end{array}$ \\
\hline
\end{tabular}

Table 6 Human attributes of the HOT-fit evaluation framework

\begin{tabular}{|c|c|c|}
\hline Group & System Use & User Satisfaction \\
\hline Across groups & $\begin{array}{l}\text { The multidisciplinary team of healthcare professionals was } \\
\text { described as main active users [35-37, 39-48, 50] } \\
\text { - One specific profession, can also have the role of the main } \\
\text { active user, where in a second step, the information is } \\
\text { shared with other passive users (providers, professions) } \\
\text { that only "consume" the information }[34,43,44] \\
\text { - Patients }[39,47,48,50] \text { administration }[36,39,42] \text { and } \\
\text { other instances like insurers or other authorities }[39,47 \text {, } \\
48,50] \text { can be passive users of the system } \\
\text { - Important that users receive ICF training to understand the } \\
\text { classification, its conceptual background and terminology } \\
{[34,35,37-40,44-48,50]}\end{array}$ & No information across papers about User Satisfaction \\
\hline $\begin{array}{l}\text { Requirement } \\
\text { Specification }\end{array}$ & Many therapists are already familiar with the ICF [34] & No information on User Satisfaction \\
\hline Development & $\begin{array}{l}\text { - Health professional students [41] can access and use the } \\
\text { system for educational purposes } \\
\text { Differentiation of the role of the administrator and the role } \\
\text { of the operator of the information system [38] }\end{array}$ & No information on User Satisfaction \\
\hline Implementation & Patients can be direct users of the system [36] & $\begin{array}{l}\text { - The new systems and corresponding tools were well ac- } \\
\text { cepted }[36,39,42,44,48,50] \\
\text { - The users were described as being motivated toward the } \\
\text { use of the ICF in EHR }[48,50] \\
\text { - The comparison and visualization of ICF structured infor- } \\
\text { mation was perceived as useful for practice }[36,39] \\
\text { - User involvement in development of the new information } \\
\text { system was described as an important aspect }[44,48,50] \\
\text { - Information load provided by the new system was not al- } \\
\text { ways perceived as ideal [36], older users can experience } \\
\text { problems in using the technology or software [36] }\end{array}$ \\
\hline
\end{tabular}


Table 7 Organization attributes of the HOT-fit evaluation framework. The organization could only be analyzed for the implementation publications

\begin{tabular}{l|l} 
Structure & Environment \\
\hline $\begin{array}{l}\text { The clinical settings were rehabilitation clinics - inpa- } \\
\text { tient }[36,42,48,50] \text { or outpatients [39] - and a neuro- }\end{array}$ & $\begin{array}{l}\text { The information system can be influenced by insurance } \\
\text { requirements [42] or the requirement of a national } \\
\text { logical unit in a hospital [44] }\end{array}$ \\
$\begin{array}{l}\text { minimal datasets [44] }\end{array}$
\end{tabular}

Table 8 Net benefit attributes of the HOT-fit evaluation framework

\begin{tabular}{|c|c|c|}
\hline Group & Benefits & Challenges \\
\hline Across groups & $\begin{array}{l}\text { - Comprehensiveness of ICF-based information and perspec- } \\
\text { tive introduces an important and valuable focus in clinical } \\
\text { practice }[34-37,39-50] \\
\text { - Standardization through the ICF enhances exchangeability, } \\
\text { comprehensiveness, consistency, and research }[35,36,39 \text {, } \\
41,43-50] \text { and can support clinical decision making }[34,37 \text {, } \\
\text { 39, 48-50] } \\
\text { - Through ICF-based reporting, quality improvement in clinical } \\
\text { process and multidisciplinary collaboration can be achieved } \\
\text { [39, 42, 48-50] } \\
\text { Improvements in time efficiency can be achieved through } \\
\text { automatic generation of ICF codes [34, 37, 40, 45] or ICF- } \\
\text { based reports [42] } \\
\text { - ICF tools can be implemented in existing information sys- } \\
\text { tems [38, 39, 41, 43, 44, 48, 50] } \\
\text { The ICF enables the focus on one professions objectives in } \\
\text { an interdisciplinary context }[34,43,44]\end{array}$ & $\begin{array}{l}\text { Difficulties to reach interoperability (e.g. ICF does not } \\
\text { meet the characteristics of a formal terminology) } \\
{[34-36,41,46,49]} \\
\text { Meaningful reduction or selection of ICF codes [36, 37, } \\
40,45,47-50] \\
\text { Periodic and consistently evaluations of the patient in- } \\
\text { formation with the ICF are necessary, to not only de- } \\
\text { scribe one time-point of the patient's functioning [36, } \\
47,48,50] \\
\text { Time-intensiveness to enable the implementation of a } \\
\text { new system }[48,50] \text { or the assignment of all relevant } \\
\text { data }[45] \\
\text { ICF definitions can differ from existing medical terms } \\
{[48,50] \text { and from general terminology [40] }}\end{array}$ \\
\hline $\begin{array}{l}\text { Requirement } \\
\text { specification }\end{array}$ & No additional information & $\begin{array}{l}\text { Challenge to find the balance between the use of free- } \\
\text { text and standardization, e.g. ICF codes [34] } \\
\text { - A crosswalk of existing measures used in practice with } \\
\text { the ICF is needed [34] } \\
\text { - Call for more data and evidence about applications and } \\
\text { value of the ICF [46] }\end{array}$ \\
\hline Development & $\begin{array}{l}\text { - Integration of all relevant information in one system, that } \\
\text { can be captured during the overall workflow }[37,38,41,43] \\
\text { - Selection tools can support ICF coding }[37,40,45]\end{array}$ & $\begin{array}{l}\text { The ICF lacks specificity in the Environmental Factor com- } \\
\text { ponent [37] }\end{array}$ \\
\hline Implementation & $\begin{array}{l}\text { Interdisciplinary work is enhanced through the ICF }[39,42 \text {, } \\
48,50] \text { with equal attention to each discipline involved [ } 48 \text {, } \\
50] \\
\text { Guidelines can be entered into the system, becoming visible } \\
\text { as a reminder at predefined stages [ } 42]\end{array}$ & $\begin{array}{l}\text { - ICF qualifiers that rate the magnitude of a problem, } \\
\text { have not been validated yet [39] } \\
\text { - Care activities cannot be classified by the ICF [44] } \\
\text { - The involvement of end-users in an adequate way when } \\
\text { implementing the new information system }[48,50]\end{array}$ \\
\hline
\end{tabular}




\section{References}

1. Holmström I, Röing M. The relation between patient-centeredness and patient empowerment: a discussion on concepts. Patient Education and Counseling 2010; 79 (2): 167-72.

2. Joseph-Williams N, Elwyn G, Edwards A. Knowledge is not power for patients: a systematic review and thematic synthesis of patient-reported barriers and facilitators to shared decision making. Patient education and counseling 2014; 94 (3): 291-309.

3. Wiljer D, Urowitz S, Apatu E, DeLenardo C, Eysenbach G, Harth T, Pai H, Leonard K. Patient accessible electronic health records: exploring recommendations for successful implementation strategies. Journal of Medical Internet Research 2008; 10 (4): e34.

4. Kalra D. Electronic health record standards. IMIA Yearbook of Medical Informatics 2006; 45: 136-44.

5. Westra BL, Delaney CW, Konicek D, Keenan G. Nursing standards to support the electronic health record. Nursing outlook 2008; 56 (5): 258-66. e1.

6. Kalra D, Fernando B, Morrison Z, Sheikh A. A review of the empirical evidence of the value of structuring and coding of clinical information within electronic health records for direct patient care. Journal of Innovation in Health Informatics 2013; 20 (3): 171-80.

7. Wiegand NM, Belting J, Fekete C, Gutenbrunner C, Reinhardt JD. All talk, no action?: the global diffusion and clinical implementation of the international classification of functioning, disability, and health. American Journal of Physical Medicine \& Rehabilitation 2012; 91 (7): 550-60.

8. Grol R, Wensing M, Eccles M, Davis D. Improving Patient Care: The Implementation of Change in Health Care. Chichester, UK: John Wiley \& Sons 2013.

9. Kostanjsek N, Rubinelli S, Escorpizo R, Cieza A, Kennedy C, Selb M, Stucki G, Üstün TB. Assessing the impact of health conditions using the ICF. Disability And Rehabilitation 2011; 33(15-16): 1475-82.

10. Cerniauskaite M, Quintas R, Boldt C, Raggi A, Cieza A, Bickenbach JE, Leonardi M. Systematic literature review on ICF from 2001 to 2009: its use, implementation and operationalisation. Disabil Rehabil 2011; 33(4): 281-309.

11. Maribo T, Petersen KS, Handberg C, Melchiorsen H, Momsen AM, Nielsen CV, Leonardi M, Labriola M. Systematic Literature Review on ICF From 2001 to 2013 in the Nordic Countries Focusing on Clinical and Rehabilitation Context. Journal of clinical medicine research 2016; 8(1): 1-9.

12. Stucki G, Bickenbach J. Functioning: the third health indicator in the health system and the key indicator for rehabilitation. European journal of physical and rehabilitation medicine 2017; 53(1): 134-8.

13. World Health Organization. International Classification of Functioning, Disability and Health. Geneva: World Health Organization (WHO) 2001.

14.ISO. ISO/TR 14639-2:2014(E) Health informatics - Capacity-based eHealth architecture roadmap Part 2: Architectural components and maturity model. Geneva: ISO; 2014.

15.ISO. BS EN 15224:2012 Health care services - Quality management systems - Requirements based on EN ISO 9001:2008. Geneva: ISO; 2012.

16. Coenen M, Cieza A, Stamm TA, Amann E, Kollerits B, Stucki G. Validation of the International Classification of Functioning, Disability and Health (ICF) Core Set for rheumatoid arthritis from the patient perspective using focus groups. Arthritis Research and Therapy 2006; 8(4): R84.

17. Kirchberger I, Coenen M, Hierl F, Dieterle C, Seissler J, Stucki G, Cieza A. Validation of the International Classification of Functioning, Disability and Health (ICF) core set for diabetes mellitus from the patient perspective using focus groups. Diabetic Medicine 2009; 26(7): 700-7.

18. Mayo NE, Poissant L, Ahmed S, Finch L, Higgins J, Salbach NM, Soicher J, Jaglal S. Incorporating the International Classification of Functioning, Disability, and Health (ICF) into an electronic health record to create indicators of function: proof of concept using the SF-12. Journal of the American Medical Informatics Association 2004; 11(6): 514-22.

19. Rastall P, Wooldridge D, Carpenter I, Hoogewerf J, Prodinger B. Perspectives of patients with long term health conditions. 2015; Available from: http://www.semantichealthnet.eu/SemanticHealthNet/assets/ File/SHN\%20288408\%20D3_3\%20rev2\%20Annex\%2010_Rastall_SHN_D3_3_final.pdf.

20.Stallinga HA, Roodbol PF, Annema C, Jansen GJ, Wynia K. Functioning assessment vs. conventional medical assessment: a comparative study on health professionals clinical decision-making and the fit with patient's own perspective of health. Journal of clinical nursing 2014; 23(7-8): 1044-54.

21. Moher D, Liberati A, Tetzlaff J, Altman DG. Preferred reporting items for systematic reviews and metaanalyses: the PRISMA statement. Journal of clinical epidemiology 2009; 62(10): 1006-12.

22. World Health Organization. How to use the ICF: A practical manual for using the International Classification of Functioning, Disability and Health (ICF). Exposure draft dor Comment. Geneva: WHO 2013.

23. Kaufman D, Roberts WD, Merrill J, Lai TY, Bakken S. Applying an evaluation framework for health information system design, development, and implementation. Nursing research 2006; 55(2 Suppl): S37-42. 
24. Krippendorff K. Content analysis. In: Papazafeiropoulou A, Stergioulas LK, editors. International encyclopedia of communication. New York: Oxford University Press 1989; 403-7.

25. Elo S, Kyngäs H. The qualitative content analysis process. Journal of advanced nursing 2008; 62(1): $107-15$.

26. Yusof MM, Kuljis J, Papazafeiropoulou A, Stergioulas LK. An evaluation framework for Health Information Systems: human, organization and technology-fit factors (HOT-fit). International Journal of Medical Informatics 2008; 77(6): 386-98.

27.Yusof MM, Papazafeiropoulou A, Paul RJ, Stergioulas LK. Investigating evaluation frameworks for health information systems. Int J Med Inform 2008; 77(6): 377-85.

28. Gray K, Sockolow P. Conceptual Models in Health Informatics Research: A Literature Review and Suggestions for Development. JMIR medical informatics 2016; 4(1): e7.

29. Eivazzadeh S, Anderberg P, Larsson TC, Fricker SA, Berglund J. Evaluating Health Information Systems Using Ontologies. JMIR medical informatics 2016; 4(2): e20.

30. Kihuba E, Gheorghe A, Bozzani F, English M, Griffiths UK. Opportunities and challenges for implementing cost accounting systems in the Kenyan health system. Global health action 2016; 9: 30621.

31.Shachak A, Montgomery C, Dow R, Barnsley J, Tu K, Jadad AR, Lemieux-Charles L. End-user support for primary care electronic medical records: a qualitative case study of users' needs, expectations and realities. Health systems (Basingstoke, England) 2013; 2(3): 198-212.

32. Talboom-Kamp EP, Verdijk NA, Blom CM, Harmans LM, Talboom IJ, Numans ME, Chavannes NH. e-Vita: design of an innovative approach to COPD disease management in primary care through eHealth application. BMC pulmonary medicine 2016; 16(1): 122.

33.ICF Research Branch. Homepage ICF Reasearch Branch. 2017 [04.05.2017]; Available from: https://www. icf-research-branch.org/.

34. Vreeman DJ, Richoz C. Possibilities and Implications of Using the ICF and Other Vocabulary Standards in Electronic Health Records. Physiotherapy Research International: The Journal For Researchers And Clinicians In Physical Therapy 2013.

35. Tanaka H, Matsumoto Y. Towards reorganization of international classification of functioning, disability and health for design of assistive robots. IEEE Workshop on Advanced Robotics and its Social Impacts, ARSO 2013: 100-5.

36. Subirats L, Ceccaroni L, Lopez-Blazquez R, Miralles F, Garcia-Rudolph A, Tormos JM. Circles of Health: towards an advanced social network about disabilities of neurological origin. Journal of Biomedical Informatics 2013; 46(6): 1006-29.

37. Frattura L, Simoncello A, Bassi G, Soranzio A, Terreni S, Sbroiavacca F, editors. The FBE development project: Toward flexible electronic standards-based biopsycho-social individual records. Studies in Health Technology and Informatics 2012.

38. Della Mea V, Fioresi V. ICF machine: a web-based system for collection of ICF data. Studies In Health Technology And Informatics 2012; 180: 1188-90.

39. Spreyermann R, Lüthi H, Michel F, Baumberger M, Wirz M, Mäder M. Long-term follow-up of patients with spinal cord injury with a new ICF-based tool. Spinal cord 2011; 49(2): 230-5.

40. Manabe S, Miura Y, Takemura T, Ashida N, Nakagawa R, Mineno T, Matsumura Y. Development of ICF code selection tools for mental health care. Methods Of Information In Medicine 2011; 50(2): 150-7.

41. Martínez NO, Sánchez SP. SIDUR: Development of an information system, using controlled vocabulary designed to the characterization and sample of population with and without disability, attended by Rehabilitation programs, University of Rosar. Revista Ciencias de la Salud 2010; 8(1): 55-67.

42. Kalwa M, Greitemann B. Technical implementation of an EDP based process documentation system for routine use in inpatient medical rehabilitation (RehaProDok) [German]. Rehabilitation 2009; 48(3): $154-9$.

43.Lehnguth R, Leidag T. OT-ASSESS [German]. Ergotherapie \& Rehabilitation 2007; 46(9): 10-4.

44.van Grunsven A, Bindels R, Coenen C, de Bel E. Developing an integrated electronic nursing record based on standards. Studies In Health Technology And Informatics 2006; 122: 294-7.

45. Kukafka R, Bales ME, Burkhardt A, Friedman C. Human and automated coding of rehabilitation discharge summaries according to the International Classification of Functioning, Disability, and Health. Journal of the American Medical Informatics Association 2006; 13(5): 508-15.

46. Giannangelo K, Bowman S, Dougherty M, Fenton S. ICF: representing the patient beyond a medical classification of diagnoses. Perspectives in Health Information Management 2005; 2: 9p.

47.Üstün TB, Chatterji S, Kostansjek N, Bickenbach J. WHO`s ICF and functional status information in health records. Health Care Financing Review 2003; 24(3): 77-88.

48. Rentsch HP, Bucher P, Dommen Nyffeler I, Wolf C, Hefti H, Fluri E, Wenger U, Wälti C, Boyer I. The implementation of the ,International Classification of Functioning, Disability and Health' (ICF) in daily prac- 
tice of neurorehabilitation: an interdisciplinary project at the Kantonsspital of Lucerne, Switzerland. Disability And Rehabilitation 2003; 25(8): 411-21.

49. Harris MR, Ruggieri AP, Chute CG. From clinical records to regulatory reporting: formal terminologies as foundation. Health Care Financing Review 2003; 24(3): 103-20.

50. Rentsch HP, Bucher P, Dommen-Nyffeler I, Wolf C, Hefti H, Fluri E, Bucher Koller ML, Deerpaul Krummenacher A, Lenherr M, Zumsteg I, Fischer M. The implementation of the ICF in daily practice of neurorehabilitation. Neurologie und Rehabilitation 2001; 7(4): 171-8.

51. Meyer T, Gutenbrunner C, Bickenbach J, Cieza A, Melvin J, Stucki G. Towards a conceptual description of rehabilitation as a health strategy. Journal of rehabilitation medicine 2011; 43(9): 765-9.

52. Timmermans S, Epstein S. A world of standards but not a standard world: toward a sociology of standards and standardization. Annual review of Sociology 2010; 36: 69-89.

53. Bales M, Kukafka R, Burkhardt A, Friedman C. Extending a medical language processing system to the functional status domain. AMIA Annual Symposium Proceedings / AMIA Symposium AMIA Symposium 2005: 888 .

54. Organization WH. How to use the ICF: A Practical Manual for using the International Classification of Functioning, Disability and Health (ICF). Geneva: WHO 2013.

55. World Health Organization. WHO ICF eLearning Tool. 2015; Available from: http://icf.ideaday.de/.

56.Swiss Paraplegic Research. ICF Case Studies. Translating Interventions into Real-Life Gains - a RehabCycle Approach. 2016; Available from: https://www.icf-casestudies.org.

57. Selb M, Escorpizo R, Kostanjsek N, Stucki G, Ustun B, Cieza A. A guide on how to develop an International Classification of Functioning, Disability and Health Core Set. European journal of physical and rehabilitation medicine 2015; 51(1): 105-17.

58.Hopfe M, Prodinger B, Bickenbach JE, Stucki G. Optimizing health system response to patient's needs: an argument for the importance of functioning information. Disabil Rehabil 2017: 1-6. 